\title{
DEMOCRACIA E LIBERALISMO
}

Recommendam os mestres não se faça confusão entre "democracia" e "liberalismo" São cousas profundamente differentes, mas que, na vida dos povos, quasi sempre se unem, de modo que os vocabulos que as indicam são vulgarmente havidos por synonymos.

\section{DEMOCRACIA}

Direi primeiramente o que entendo por democracia, e, em seguida, explicarei o que julgo ser liberalismo.

Os chefes que se impuzeram aos homens da tribu primitiva pela violencia, na qualidade de mais fortes, quizeram legitimar sua autoridade dizendołse emissarios de Deus. O "por mim reinam os reis", e o "por mim distinguem os legisladores o justo do injusto", são fórmulas que traduzem esta doutrina com grande felicidade. A par do soldado feliz que foi o primeiro rei, a par da violencia, surgiu na conquista do poder, do mesmo modo que em outros tantos phenomenos sociaes, o recurso á fraude: thronos obtidos pela força, e thronos alcançados pela fraude.

O povo porém, que não é tão nescio quanto se diz, cedo começou a pôr em duvida essa origem divina do poder dos chefes. Não podia acceitar que os terrificos monstros da estofa de Luiz XI e Luiz XV fossem enviados do bom Deus, e que os legisladores que só buscam interesse no seu grupo promulgassem suas normas por inspiração divina. Logo, na vida da humanidade, começou o fermento da descrença no seio da sociedade, e, na Roma antiga, já encon- 
tra-se o povo, embora com muita difficuldade, legislando para si mesmo, na praça publica, em comicios. Manteve-se todavia o poder dos chefes com caracter de poder divino até nossos dias, como se viu na Russia dos Czares e na Allemanha dos Hoenzollerns. O mais digno de nota porém é a pretenção de certos presidentes de republica, tidos por muitas pessoas como sendo atacados da mania religiosa, de se affirmarem representantes de Deus.

Os que negam absolutamente a intervenção divina no estabelecimento do governo são os que asseveram vir 0 poder da vontade do povo.

Ha muitas escolas médias, sustentando que o poder vem, sim, do povo, mas é concedido a este por Deus. Si em um Estado é esiabelecido que a autoridade governa por méra delegação popular, o regimen é democratico. $\mathrm{Na}$ nossa antiga constituição de 1824 , foi instituido um regimen mixto: D. Pedro se dizia imperador "por graça de Deus e unanime acclamação dos povos"

Ha ainda uma differença notada pelos constitucionalistas. Por "democracia" entendem elles a "democracia pura", como existe em varios cantões da Suissa: não ha delegação de poderes do povo a certos individuos, mas 0 povo resolve directamente sobre os negocios publicos no comicio. Quando ha uma delegação, quando o regimen é representativo, mas prevalece nelle o conceito de que o povo tem na autoridade um simples mandatario, obrigado a agir de accordo com a vontade popular, ha o regimen democratico

Nestes ultimos tempos, depois das criticas ao Direito Divino, quando já era impossivel continuar a pretender-se que os reis e chefes de Estado são ungidos do Senhor, surgiu uma doutrina a que faltam alicerces: é a de haver na sociedade uma classe superior ("escól ou élite") que deve dirigir o paiz. Mas qual o fundamento dessa pretensão? Em que consiste, além disto, a superioridade dessa classe? 
Será o favor divino por serem os membros dessa oligarchia santos, como succedia na india e em outros lugares, onde predominou a theocracia? Será a bravura na guerra como aconteceu em Roma, ou o regimen da estratocracia? Será a riqueza, a qual era o criterio onde se instituiu a irocracia ou plutocracia?

Houve sempre combinações mais ou menos ardilosas, compondo-se as oligarchias com membros que se diziam bravos, santos ou ricos. Não nego que os homens de certa cultura possam dar, com felicidade, seu parecer, quando urn povo se encontra em difficil posição Mas os proprios sabios serão despotas desde que tenham em suas mãos o governo: despotismo esclarecido ou illuminado. Demais, como determinar quem é o sabio? Não tem sido, quasi sempre, uma burla a criação de consultores e de conselheiros para os administradores? Serão raros, neste mundo, os $\mathrm{Pa}$ checos?

Mas. em vez de me limitar a dizer o que é a democracia, estou a fazer a apologia do governo do povo pelo povo. Passo a outro ponto.

\section{LIBERALISMO}

Querem os liberaes que o governo seja reduzido ao minimo: é o que explicam com a formula "minimo ethico exigivel" Pode ser considerado como tendo sido um dos primeiros a estabelecer o principio liberal Giordano Bruno, queimado em Roma, no Campo das Flores, a 17 de fevereiro de 1600 , sendo seu principal crime haver sustentado que deve ser limitada a acção do Estado a reprimir os actos que profundamente perturbam a paz social. Nas cinzas desse martyr dnveria germinar a semente da doutrina liberal, que condemna o Estado regulamentador, o Estado a immiscuir-se em actos indifferentes para a sociedade, e destinado, ás mais das vezes, a proteger um grupo. E' contra a intervenção do Estado nos actos menos importantes da vida social que se levanta a escola liberal. 
Ramifica-se em varias sub-escolas. Algumas dellas, como sóe sempre acontecer, exageram os principios fundamentaes do liberalismo. Dessas, a mais conhecida é a que é vulgarmente denominada a do "Estado Gendarme" O fim do Estado é, para ella, policiar e distribuir justiça. A formula "laiser faire, laiser passer", e a que diz "il mondo va da se" exprimem uma verdade incontestavel. Em casos excepcionaes, porém, julgo eu, quando o particular por si só não pode conseguir certo escopo util á communhão, indispensavel se torna auxilie o poder publico a iniciativa individual.

Mas a cultura civica ministrada pelo Estado é tudo quanto ha de mais perigoso para a vida social, e para a liberdade publica. Tem-se dicto e repetido, um sem numero de vezes, que o mestre escola allemão venceu em Sedan. Mas como venceu? Explica muito bem Julio Benda que, nas escolas de Allemanha, durante muitos annos, na formação de uma geração, se envenenou a mocidade prégando-lhe 0 odio aos francezes. Para ter accesso, e para evitar ser perseguido, força era ao mestre escola prégar a doutrina que se contém no "Deutschland über alles": era a ordem do Kaiser Todo o Direito Publico estava contido nesta frase de Treitsohke: "Duas funcções cabem ao Estado: distribuir justiça e "fazer guerra" Mas a guerra é a principal" Eis o que foi a cultura ministrada na escola pelo mestre allemão, ensinança que arrastou o laborioso povo, digno de melhor sorte, a esmagar a briosa França em Sedan, e que, mais tarde, transformou o mundo em um sanguineo campo de batalha, durante a grande guerra.

\section{REgulamentaÇão}

A regulamentação contra a qual, na qualidade de discipulo de Stuart Mill, Laboulaye e outros espiritos de alta reputação entre os letrados, sempre me manifestei, como se póde ver na Revista da Faculdade de Direito, vol 18 pag. 159 e vol. 19 pag. 157, foi um verdadeiro flagello na 
Allemanha. Para Anatolie França transformára-se o bello paiz em um quartel em que tudo era regido por normas legaes, até o abandono de um pequeno jornal no banco de um. jardim publico. Só dessas regrinhas estavam isentos.

os militares: esses podiam, diversamente dos paisanos, andar nas calçadas como thes aprouvesse, quando os outros mortaes deveriam ir por uma e voltar por outra. O grande escriptor francez só teve um momento de socego, e foi quando conseguiu, em um botequim, encontrar um recanto onde ficasse livre dos olhos vigilantes dos guardas do respeito aos regulamentos. Sabido é que o mais pobre agricultor e o mais modesto vendedor ambulante só podiam mandar fazer uma carrocina sob um padrão preestabelecido. porque podia bem succeder que, em caso de guerra, fosse $o$ vehiculo requisitado!!!! A guerra eis o fantasma, a origem da regulamentação. Mas, dir-me-ão a Allemanha se desenvolveu sob esse regimen. Responderei: desenvolveu-se "não obstante" esse monstruoso regimen, "sem embargo de" tal regulamentação. Finda porém a guerra, livre já o allemão do avantesma, em menos de dez annos reconquistou o lugar que nos mercados do mundo perdêra em consequencia da maldicta luta a que o arrastára o Kaiser Não fosse o povo laborioso, e o Kaiser teria conseguido arruinal-o .

\section{Algumas minucias}

Póde haver uma democracia que não seja liberal. Admitta-se, que algum dos cantões da Suissa regidos pela democracia pura entendesse de formular normas para tudo: limitação dos gastos julgados sumptuarios, prohibição de lançar a menor parcella de papel na via publica, regulamentação do traje, determinações inuteis sobre o padrão dos vehiculos, medidas inuteis, ou estupidas sobre o transito, prescripções sobre os medicamentos a serem usados pelos cidadãos. e tudo sob a fiscalização de tyrannicos mazorros. Seria uma democracia pouco liberal: uma democracia que mediria o ar que os cidadãos respiram. Mas isto não se 
dará provavelmente, porque os cidadãos têm outras occupações que não essas futilidades, e, além disto, não hão de querer submetter-se a tantas restricções postas á sua liberdade. Em sentido contrario, figure-se um monarcha absoluto e dotado de intelligencia e illustração. Convencido de que é muitissimo mais facil para elle, e muitissimo mais proveitoso para seu povo deixar que actuem na vida social as forças naturaes do que impor seu capricho, abster-se-á de regulamentar os actos de importancia minima ou secundaria de seus subditos, só fazendo leis sobre pontos vitaes, capitaes, cujo abandono pelo legislador traria necessaria e evidentemente a ruina, a subversão da organização social. Esse monarcha imaginario teria instituido um regimen liberal em seus dominios.

\section{CONCLUSÃO}

Lei sociologica a ser estabelecida é a de que "quanto mais dura é a tyrannia tanto maior é o numero de preceitos legislativos", como tão bem observou Tacito. Regulamentação é synonymo de despótismo na vida pratica. Liberalismo é synonymo de democracia, mas só pelo aspecto pratico.

Ha ainda uma synonymia que denominarei tambem practica, e que é a seguinte. Como o regimen democratico significa o que representa a vontade popular, não se comprehende revolução dentro delle: executado com lealdade dará satisfação ao povo e consequentemente paz. Como o regimen opposto em que predomina na sociedade a vontade do chefe contra a da multidão, podendo aquelle dizer, do mesmo modo que o biographo do Garcia Moreno, o Padre Berthe, "um só contra todos", o regimen contrario ao democratico, qualquer que seja sua modalidade, representa, constituindo um eterno desgosto para o povo, um factor das revoluções. Os ultimos exemplos comprobatorios desta verdade são a Russia e a China

$$
\text { JoÁo Arruda. }
$$

